\title{
Renal Pseudoaneurysms and Arteriovenous Fistulas as a Complication of Nephron-Sparing Partial Nephrectomy: Technical and Functional Outcomes of Patients Treated With Selective Microcoil Embolization During a Ten-Year Period
}

\author{
Interventionelle Behandlung renaler Pseudoaneurysmen und AV-Fisteln als Komplikation \\ nach partieller Nephrektomie: Technische und funktionelle Ergebnisse von allen mit selektiver \\ Microcoil-Embolisation behandelter Patienten eines 10-Jahres-Zeitraums
}

Authors

Affiliations
F. F. Strobl', M. D'Anastasi' ${ }^{1}$, R. Hinzpeter ${ }^{1}$, P. S. Franke', C. G. Trumm¹', T. Waggershauser ${ }^{1}$, M. Staehler ${ }^{2}$, D. A. Clevert ${ }^{1}$, M. Reiser ${ }^{1}$, A. Graser ${ }^{1}$, P. M. Paprottka ${ }^{1}$

1 Institute for Clinical Radiology, Ludwig-Maximilians-University Hospital, Munich, Germany

2 Department of Urology, Ludwig-Maximilians-University Hospital, Munich, Germany

\author{
Key words \\ - embolization \\ renal arteries \\ - angiography \\ - interventional procedures
}

received $\quad 3.8 .2015$

accepted $\quad 21.10 .2015$

\section{Bibliography}

Dol http://dx.doi.org/ 10.1055/s-0041-110136

Published online: 12.1.2016

Fortschr Röntgenstr 2016; 188: 188-194 @ Georg Thieme

Verlag KG Stuttgart · New York . ISSN 1438-9029

\section{Correspondence \\ Frederik F. Strobl}

Institute for Clinical Radiology,

Ludwig-Maximilians-University

Hospital, Munich

Marchioninistr. 15

81377 München

Germany

Tel.: ++ 49/89/440073620

Fax: ++49/89/440 078832

frederik.strobl@med.Imu.de

\section{Zusammenfassung \\ $\nabla$}

Ziel: Das Ziel dieser Studie war das klinische und funktionelle Ergebnis der Patienten zu untersuchen, die mit einer interventionellen, selektiven Embolisation von renalen Pseudoaneurysmen oder AV-Fisteln an unserer Klinik behandelt wurden.

Material und Methoden: Diese retrospektive Studie schloss alle konsekutiven Patienten ein, die zwischen 2003 und 2013 an unserer Klinik eine selektive Katheter-gestützte Embolisation eines renalen Pseudoaneurysmas oder einer AV-Fistel nach partieller Nephrektomie erhielten. Es wurde die technische und klinische Erfolgsrate sowie das funktionelle Ergebnis von allen Interventionen analysiert. Zusätzlich wurde in einer Subgruppe der Einfluss der Intervention auf das Parenchymvolumen der behandelten Niere untersucht.

Ergebnisse: Insgesamt wurde zwischen 2003 und 2013 in unserer Klinik bei 1425 Patienten eine partielle Nephrektomie durchgeführt. Von diesen wurden 39 Patienten $(2,7 \%)$ zur interventionellen Behandlung eines renalen Pseudoaneurysmas oder einer AV-Fistel überwiesen. Bei allen Patienten wurde diese Diagnose durch eine biphasische CT Untersuchung oder eine kontrastverstärkte Ultraschalluntersuchung (CEUS) bestätigt. Insgesamt konnte ein primärer technischer Erfolg bei $39 \mathrm{~Pa}$ tienten $(100 \%)$ durch eine selektive Embolisation mit Microcoils erreicht werden. Ein klinischer Erfolg, definiert durch eine fehlende Notwendigkeit zur weiteren Operation oder Nephrektomie wurde in 35 von 39 Patienten erreicht (85,7\%). Die präund postinterventionelle GFR zeigte keine signifikante Änderung $(p>0,05)$. Jedoch wurde ein Verlust des renalen Parenchymvolumens von 25,2\% in einer Subgruppe festgestellt. Bezogen auf die interventionelle Prozedur zeigten sich keine major oder minor Komplikationen.

Schlussfolgerung: Eine kathetergesteuerte Embolisation ist eine erfolgsversprechende organerhal-

\section{Abstract \\ V}

Purpose: The aim of this study was to evaluate the clinical and functional outcomes in patients who underwent selective interventional embolization of renal pseudoaneurysms or arteriovenous fistulas at our center.

Materials and Methods: Our retrospective analysis included all consecutive patients who received selective transcatheter embolization of renal pseudoaneurysms or arteriovenous fistulas after partial nephrectomy in our department from January, 2003 to September, 2013. The technical and clinical success rate and functional outcome of every procedure was collected and analyzed. Furthermore, the change in renal parenchymal volume before and after embolization was determined in a subgroup.

Results: A total of 1425 patients underwent partial nephrectomy at our hospital. Of these, 39 (2.7\%) were identified with a pseudoaneurysm or an arteriovenous fistula after partial nephrectomy. The diagnosis of the vascular lesions was made by means of biphasic CT or CEUS. Technical success by means of selective microcoil embolization was achieved in all 39 patients (100\%). Clinical success, defined as no need for further operation or nephrectomy during follow-up, was achieved in 35 of 39 patients ( $85.7 \%$ ). Renal function, as measured by eGFR before and after the intervention, did not change significantly. However, a mean loss of parenchymal volume of $25.2 \%$ was observed in a subgroup. No major or minor complications were attributable to the embolization procedure.

Conclusion: Transcatheter embolization is a promising method for treating vascular complications which may occur after partial nephrectomy. We confirm the high success rate of this technique while discussing renal functional outcomes and potential safety aspects. 
tende Methode zur Behandlung vaskulärer Komplikationen, die nach partieller Nephrektomie auftreten können. Wir bestätigen die hohe Erfolgsrate dieser Technik und analysieren funktionelle renale Endpunkte sowie Sicherheitsaspekte.

Kernaussagen:

- Arterielle Pseudoaneurysmen oder arteriovenöse Fisteln sind seltene, jedoch schwerwiegende Komplikationen nach partieller Nephrektomie

- Die selektive Mikrocoil Embolisation ist ein sicheres nierenerhaltendes Verfahren zur Behandlung dieser Komplikationen

- Die Embolisation führt zu einem signifikanten Verlust des Nierenparenchymvolumens aber zu keinem renalen Funktionsverlust
Key points:

- Arterial pseudoaneurysms and arteriovenous fistulas are rare but severe complications after partial nephrectomy

- Selective microcoil embolization is a safe and effective kidneypreserving procedure for treating these complications

- Embolization leads to a significant loss of renal parenchymal volume but not to a loss of renal function

Citation Format:

- Strobl FF, D'Anastasi M, Hinzpeter R et al. Renal Pseudoaneurysms and Arteriovenous Fistulas as a Complication of $\mathrm{Ne}-$ phron-Sparing Partial Nephrectomy: Technical and Functional Outcomes of Patients Treated With Selective Microcoil Embolization During a Ten-Year Period. Fortschr Röntgenstr 2016; 188: $188-194$

\section{Introduction}

Partial nephrectomy is a well-established operative procedure for the treatment of renal tumors $[1,2]$. This nephron-sparing surgery shows similar oncologic outcomes when compared to total nephrectomy [3-5]. In addition, it is associated with a lower risk of post-operative chronic renal failure $[3,6,7]$. However, partial nephrectomy increases the risk of iatrogenic vascular lesions, such as pseudoaneurysms and arteriovenous fistulas, due to the highly vascularized renal parenchyma $[8,9]$. They are rare but serious complications which can lead to severe hematuria, blood loss, and hemorrhagic shock $[8,10]$.

It has been reported that these arterial lesions can be treated successfully with minimally invasive selective transcatheter embolization [11 - 14]. However, the published studies on this topic are relatively small, with the largest study to date, to our knowledge, reporting about a cohort of 28 patients [11]. In addition, the effects of embolization on quantitative renal parenchymal volume and procedure-related radiation dose have not been previously reported.

Therefore, this study was performed to further define the role of embolization in the management of renal vascular lesions after partial nephrectomy. The purpose of this study was to evaluate all consecutive patients who received transcatheter embolization for the treatment of renal vascular complications after partial nephrectomy at our institution. Technical and clinical successes, radiation doses, and the influence of the embolization on renal function and volume are reported.

\section{Materials and Methods}

$\boldsymbol{\nabla}$

\section{Patients and technical and functional outcomes}

All consecutive patients who underwent angioembolization of iatrogenic vascular lesions due to partial nephrectomy were identified through a search of our database, which includes all radiological interventions performed at our department. Medical charts, laboratory investigations, and radiological reports of all patients were carefully reviewed to determine technical and functional outcomes of the interventions. Glomerular filtration rate (GFR) was determined one day before and one day after partial nephrectomy as well as one day before and one day after angioembolization. GFR was estimated using the Cockcroft-Gault equation with the parameters age, sex, and serum creatinine levels [15]. Technical success was defined as successful primary angiography-guided occlusion of the arterial lesion. Clinical success was defined as no need for nephrectomy or further operation on the vascular lesion during follow-up.

\section{Pre-interventional imaging}

In all patients, pre-interventional imaging was performed to localize and confirm the clinically suspected vascular lesion. Patients underwent a biphasic contrast-enhanced CT examination consisting of an arterial and venous phase of the abdomen as the primary imaging modality. In patients with severely reduced GFR, contrast-enhanced ultrasound was performed as an alternative imaging modality. CT examinations were performed on a 64or 128 -row scanner (Siemens Healthcare ${ }^{\circledR}$, Erlangen, Germany) with the use of $1.5 \mathrm{ml}$ of contrast agent per $\mathrm{kg}$ of body weight (Imeron $400^{\circledR}$, Bracco Imaging, Konstanz, Germany) followed by a bolus of $100 \mathrm{ml}$ of sodium chloride. Sonographic evaluation consisted of an examination using B-mode, color duplex ultrasound, and contrast-enhanced sonography. Contrast-enhanced sonography was performed after injection of $0.8-1 \mathrm{ml}$ of contrast agent consisting of microbubbles (SonoVue ${ }^{\circledR}$, Bracco, Milan, Italy) followed by a bolus of $10 \mathrm{ml}$ of $\mathrm{NaCl}$. Ultrasound examinations were carried out either on a LOGIQ E9 ${ }^{\circledR}$ (GE Healthcare ${ }^{\circledR}$, Little Chalfont, United Kingdom) or an $\mathrm{S} 2000^{\circledR}$ (Siemens Healthcare $^{\circledR}$, Erlangen, Germany).

\section{Interventions}

Through a femoral access, a renal angiogram was first performed to localize the vascular lesion using a $4 \mathrm{~F}$ cobra catheter $\left(\right.$ Terumo ${ }^{\circledR}$, Tokyo, Japan). Afterwards, superselective catheterization of the bleeding vessel was performed using a coaxial microcatheter system (Progreat ${ }^{\circledR}$, Terumo, Tokyo, Japan). When a stable catheter position was obtained, coil embolization was performed until complete occlusion of the vascular lesion was achieved. The coil type used depended on the preference of the interventionalist. The types and sizes of the coils used will be presented in the results section. All interventions were performed by board-certified interventional radiologists with at least five years of experience in embolization procedures.

\section{Volumetric analysis}

Axially reconstructed images with 5-mm slice thickness from the pre- and post-interventional CT scans in the portal venous phase were used for volumetric analysis. This was performed using semi-automated volumetric software (Siemens Syngo.via ${ }^{\circledR}$ Oncology, Siemens Healthcare ${ }^{\circledR}$ ). A digital dash was drawn across the whole kidney, after which a volumetric segmentation of the kidney was obtained. Manual correction of the contours was 
then performed. The two volumes obtained (pre- and post-intervention) were recorded and the volume shrinkage between preand post-intervention was calculated. Volumetric measurements were performed in consensus by two diagnostic radiologists, one with three years and the other with six years of experience in this procedure.

\section{Ethics statement}

All investigations have been conducted according to the principles expressed in the Declaration of Helsinki. All patient records and information was anonymized and de-identified prior to analysis. Therefore, and due to the strictly retrospective design of the study, no written informed consent was obtained by the participants. The institutional review board of the ethics committee of Ludwig-Maximilians-University confirmed the study with a certificate of compliance (No.526-15 UE).

\section{Statistical analysis}

Categorical variables are presented as absolute and relative frequencies. For descriptive data with normal distribution, mean \pm standard deviation (SD) was given, and comparisons were performed by a 2-sided $t$ test. A p-value $<0.05$ indicated statistical significance. All analyses were performed using SPSS ${ }^{\circledR}$ software (version 20, IBM SPSS Inc.).

\section{Results}

$\nabla$

Between January, 2003 and September, 2013, a total of 1425 patients underwent partial nephrectomy at our institution.

Of these, 39 (2.7\%) were referred to our department for transcatheter embolization of pseudoaneurysms or arteriovenous fistulas (mean age 65.7 years; 30 males, 9 females). Baseline demographics of the cohort are given in 0 Table 1. In total, we had 26 patients with at least one renal pseudoaneurysm, 12 patients with AV-fistulas, and 1 patient with a pseudoaneurysm and an additional AV-fistula. The patients of this study underwent open, laparoscopic, or robot-assisted surgery; the greatest proportion $(82.1 \%$ ) was treated with open partial nephrectomy.

Patients presented clinical symptoms of the vascular lesion 15.3 days (mean) after partial nephrectomy. Diagnosis was established by biphasic CT in $92.3 \%$ of cases and by CEUS in $7.7 \%$ of cases. Occlusion of the vascular lesion was accomplished with a mean of 4 coils (range 1 - 26). Tornado ${ }^{\circledR}$ coils (Cook, Bjaeverskov, Denmark) with a size range of $3-10 \mathrm{~mm}$ were used in 36 patients. An Interlock occlusion system ${ }^{\circledR}$ (Boston Scientific ${ }^{\circledR}$, Marlborough, MA, United States) was employed in two patients (Interlock coils with a size of $6 \times 100 \mathrm{~mm}$ in one patient and one Interlock coil with a size of $12 \times 200 \mathrm{~mm}$ in the other patient). A detachable HydroCoil (Azur ${ }^{\circledR}$, Terumo, Tokyo, Japan) was used for embolization in one patient. The mean intra-interventional dose area product was $8563 \mathrm{cGy} \times \mathrm{cm}^{2}$ (range 1287-36701 $\mathrm{cGy} \times \mathrm{cm}^{2}$ ). Characteristics of the interventions are shown in - Table 2.

Overall, primary coil embolization was technically successful in 39 patients (100\%). However, a second intervention with additional embolization was necessary for two patients in this group (5.1\%). Clinical success, with no need for further operation or nephrectomy, was achieved in 35 patients (89.7\%). Four patients (10.3\%) had to undergo surgery after angioembolization due to persistent blood loss and hematuria. In three of these four patients, persisting clinical symptoms were severe enough that total nephrectomy had
Table 1 Baseline demographics.

Tab. 1 Demografische Daten zu Studienbeginn.

\begin{tabular}{|l|l|}
\hline characteristics & $\begin{array}{l}\text { number (percentage) or } \\
\text { mean } \pm \text { SD (range) }\end{array}$ \\
\hline total number of patients & $39(100)$ \\
\hline sex & $30(76.9)$ \\
\hline - male & $9(23.1)$ \\
\hline - female & $65.7 \pm 11.8(32-81)$ \\
\hline age, mean \pm SD (range) in years & $3.8 \pm 1.6(1.2-8.5)$ \\
\hline tumor size, mean \pm SD (range) in cm & \\
\hline operative approach & $32(82.1)$ \\
\hline - open & $4(10.3)$ \\
\hline - laparoscopic & $3(7.6)$ \\
\hline - robot-assisted & \\
\hline
\end{tabular}

Table 2 Intervention characteristics.

Tab. 2 Interventionscharakteristika.

\begin{tabular}{|lc|}
\hline characteristics & $\begin{array}{c}\text { number (percentage) or } \\
\text { mean } \pm \text { SD/median (range) }\end{array}$ \\
\hline days from operation to intervention & $15.3 \pm 9.7(3-43)$ \\
\hline imaging modality to confirm diagnosis & \\
\hline - biphasic CT & $36(92.3)$ \\
\hline - contrast-enhanced US & $3(7.7)$ \\
\hline number of coils used & $4(1-26)$ \\
\hline dose area product in cGy $\times \mathrm{cm}^{2}$ & $8563(1287-36701)$ \\
\hline fluoroscopy time in minutes & $13(2.5-31.4)$ \\
\hline
\end{tabular}

Table 3 Changes in GFR.

Tab. 3 Änderungen der GFR.

\begin{tabular}{lll}
$\begin{array}{l}\text { mean GFR before } \\
\text { partial nephrectomy }\end{array}$ & $\begin{array}{l}\text { mean GFR one day after } \\
\text { partial nephrectomy }\end{array}$ & $\mathrm{p}<0.01$ \\
$64.75 \mathrm{ml} / \mathrm{min}$ & $48.82 \mathrm{ml} / \mathrm{min}$ & \\
$\begin{array}{ll}\text { mean GFR before } \\
\text { embolization }\end{array}$ & $\begin{array}{l}\text { mean GFR one day after } \\
\text { embolization }\end{array}$ & \\
\hline $50.88 \mathrm{ml} / \mathrm{min}$ & $50.96 \mathrm{ml} / \mathrm{min}$ &
\end{tabular}

to be performed, and in one patient an operative revision with suturing of the arterial lesion was performed. Examples for successful interventions and preinterventional imaging are presented in॰ Fig. 1, 2 .

No typical complications of invasive angiography, such as dissections, groin hematoma, or bleeding, were observed in any intervention. Although there was a significant reduction of GFR between the pre-operative and post-operative days, there was no significant difference of GFR between the pre-embolization and post-embolization days. Details about the analysis of renal function are given in $\bullet$ Table 3.

Determination of renal loss of volume could be determined in a subgroup of $n=10$. In the remaining 29 patients, post-interventional renal volume could not be determined because patients were either lost to follow-up or underwent follow-up in a different hospital or private practice or underwent follow-up by MRI. All pre-interventional volume measurements were performed in the CT scan before embolization. Post-interventional volume was measured in the first post-interventional CT scan, which 

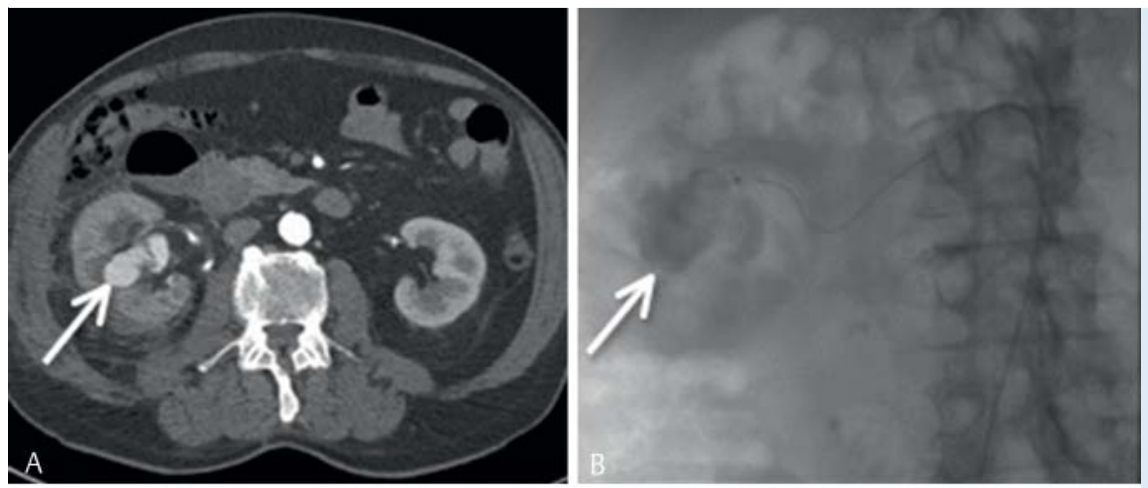

Fig. 1 A Contrast-enhanced CT demonstrating a renal artery pseudoaneurysm (white arrow) of $4.4 \times 2.3 \mathrm{~cm}$ after partial nephrectomy on the right side. B Angiography confirms the pseudoaneurysm (white arrow) of the upper renal artery. C Successful embolization of the feeding vessel of the pseudoaneurysm with six microcoils, which were deployed via a co-axial system. D Postinterventional CT demonstrating complete occlusion of the feeding vessel of the vascular lesion with microcoils.

Abb. 1 A CT nach KM zeigt ein renales Pseudoaneurysma (weißer Pfeil) mit Größe von 4,4×2,3 cm nach partieller Nephrektomie rechts. B Angiogra-
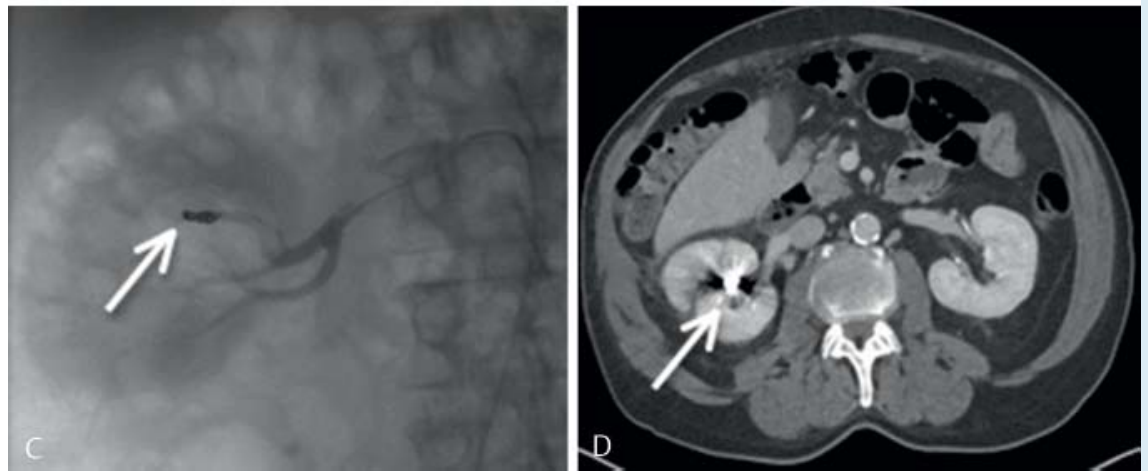
fische Bestätigung des Pseudoaneurysma (weißer Pfeil) des Nierenoberpolarterie. C Erfolgreiche Embolisation des zuführenden Gefäßes des Pseudoaneurysmas mit 6 Microcoils welche durch ein coaxiales System eingebracht wurden. D Postinterventionelles $\mathrm{CT}$ zeigt einen kompletten Verschluss des zuführenden Gefäßes der vaskulären Läsion mit Microcoils.

Table 4 Changes in renal volume in each patient of $\mathrm{n}=10$.

Tab. 4 Änderungen des Nierenvolumens in jedem Patienten von $\mathrm{n}=10$.

\begin{tabular}{|llll|}
$\begin{array}{l}\text { patient } \\
\text { number }\end{array}$ & $\begin{array}{l}\text { renal volume } \\
\text { (ml) before } \\
\text { embolization }\end{array}$ & $\begin{array}{l}\text { renal volume (ml) } \\
\text { after embolization } \\
\text { (Median 100 d) }\end{array}$ & $\begin{array}{l}\text { loss of volume } \\
\text { (\%) }\end{array}$ \\
\hline 1 & 137 & 124 & 9.5 \\
\hline 2 & 192 & 169 & 12 \\
\hline 3 & 182 & 154 & 15.4 \\
\hline 4 & 160 & 135 & 15.6 \\
\hline 5 & 143 & 114 & 20.3 \\
\hline 6 & 176 & 139 & 21 \\
\hline 7 & 184 & 127 & 31 \\
\hline 8 & 117 & 80 & 31.6 \\
\hline 9 & 165 & 97 & 41.2 \\
\hline 10 & 186 & 85 & 54.3 \\
\hline & mean loss of volume: $25.2 \pm 14.3 \%(p<0.05)$ \\
\hline
\end{tabular}

was performed 100 days (median) after embolization. Mean renal volume loss was $25.2 \pm 14.3 \%$ between the pre- and post-interventional CT scans, which is a significant loss ( $p<0.05)$. Examples of the volumetric measurements are presented in $\bullet$ Fig. 3. Details about volume measurements are given in $\bullet$ Table 4.

\section{Discussion}

\section{Dis}

Pseudoaneurysms and arteriovenous fistulas are rare post-operative complications of nephron-sparing partial nephrectomy. At our center, we identified 39 of 1425 patients treated with nephron-sparing surgery ( $2.7 \%$ ) as being affected by one of these iatrogenic lesions. This complication rate is consistent with other reports published in the literature [11, 16-19]. Since these complications are potentially life-threatening, it is mandatory to achieve a reliable diagnosis when patients present signs and symptoms potentially indicative of pseudoaneurysms and/or arteriovenous fistulas. Unfortunately, these are often unspecific (as in the case of hematuria, flank pain, hypotension, and fever) or delayed in their occurrence. It has been reported that some patients were even asymptomatic and that the pseudoaneurysms or arteriovenous fistulas in these patients were detected incidentally during examinations for follow-up or another condition [17].

Most of our patients (82.1\%) diagnosed with either pseudoaneurysms or arteriovenous fistulas had undergone open partial nephrectomy, while $10.3 \%$ and $7.6 \%$ were treated with laparoscopic and robot-assisted procedures, respectively. This is in contrast to other reports where a slightly higher occurrence is observed when patients received laparoscopic surgery $[12,17]$. This discordance could be explained by the lack of large-scale randomized trials and, possibly, the failure to take confounding factors into account. In addition, a selection bias might be present, given the fact that patients with larger tumors with difficult anatomy, such as a central location, and previously operated patients are more likely to undergo open nephrectomy, which might explain the higher rate of patients being treated with open nephrectomy in our cohort. As yet, no clear reason is known why one or the other surgical procedure would predispose a patient to these vascular complications [20].

Several diagnostic approaches were demonstrated as suitable for the assessment of pseudoaneurysms or arteriovenous fistulas following partial nephrectomy. In $92.3 \%$ of our patient group, CT was used for pre-interventional imaging. This technique has the advantage of not only the detection of pseudoaneurysms and arteriovenous fistulas but also the diagnosis of other intra-abdominal pathologies such as hematoma or urinary retention. Moreover, MDCT is a fast and reliable method [16]. However, pseudoaneurysms may be difficult to differentiate from adjacent arteries. Thus, negative CT-examinations cannot definitely exclude pseudoaneurysms and additional investigations may have 


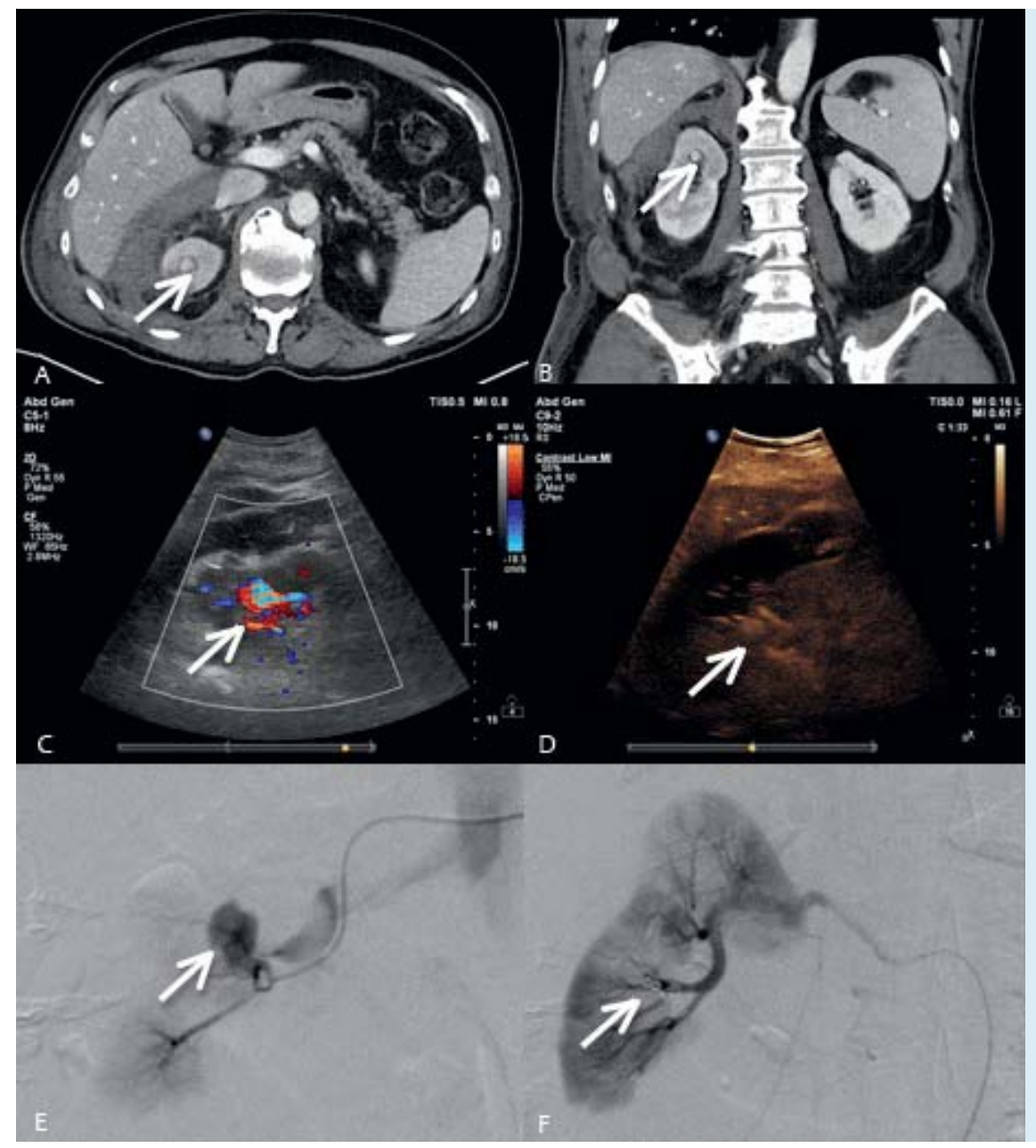

Fig. 2 A Contrast-enhanced CT showing an arterial lesion (arrow) of $10 \times 8 \mathrm{~mm}$ and a perirenal hematoma at the upper pole of the right kidney. B Coronal MPR of the CT-scan. C Doppler sonography shows the blood flow of an AV-fistula with the feeding artery and the draining vein. D CEUS confirms the AV-fistula. E Angiographic catheter position before embolization, the AV-fistula is visible (white arrow). F Successful microcoil embolization of the artery, which fed the AV-fistula.

Abb.2 A CT nach KM zeigt eine arterielle Läsion (Pfeil) mit Größe von $10 \times 8 \mathrm{~mm}$ und ein perirenales Hämatom um den Oberpol der rechten Niere. B Koronare MPR der CT-Aufnahmen. C Dopplersonografie zeigt den Blutfluss der AV-Fistel mit zuführender Arterie und abführender Vene. D Bestätigung der AV-Fistel durch CEUS. E Angiografische Katheterlage vor Embolisation, die AV-Fistel ist sichtbar (Pfeil). F Erfolgreiche Microcoil-Embolisation des zuführenden arteriellen Gefäßes der AVFistel.

to be performed [12]. In patients with severely impaired renal function, the use of nephrotoxic contrast media can pose an unacceptably high risk. In these cases, contrast-enhanced ultrasound or MRI without contrast agents are more suitable. For this reason, diagnostic imaging of our patients with a severely lowered eGFR (7.7\%) was performed utilizing contrast-enhanced ultrasound. However, contrast-enhanced ultrasound is highly dependent on the experience and knowledge of the performing physician. Therefore, it may not be readily available in many institutions.

Even if CECT and CEUS are preferred because of their non-invasive nature, percutaneous angiography may be required although it presents a higher morbidity and mortality risk and cannot image the entire urinary tract [18]. When there is a strong suspicion of a pseudoaneurysm or an arteriovenous fistula, angiography with a subsequent embolization procedure may be a straightforward approach [13]. Despite these alternative options, however, CECT is the first choice both for diagnosis and for follow-up unless substantial contraindications exist [18].

In our cohort, symptoms indicating the existence of a vascular lesion and the consecutive positive diagnoses thereof appeared 15.3 days (mean; range 3-43 days) after partial nephrectomy. This time interval corresponds to findings in the literature which show that pseudoaneurysms or arteriovenous fistulas were detected from one day up to several months after surgery, with an approximate mean of between 8 and 15 days [11, 12, 17, 18, $21,22]$. In one small study, the longest interval between opera- tion and clinical symptoms was even 3 months [23]. The largest study on this topic, which was recently published, examined the timing and indications of transcatheter angiographic embolization for delayed hemorrhage after percutaneous nephrolithotomy in 144 patients [24]. Their reported mean time to the onset of post-nephrolitomy hemorrhage was 10.5 days (range $2-30$ days), which is in line with our results after partial nephrectomy. These observations underline the need for alertness when symptoms begin to manifest within the follow-up period.

Selective embolization of the leaking arteries was accomplished by complete occlusion of the feeding arteries using microcoils. According to the interventionalists' preferences, several types of coils were utilized. In most cases (36 of 39 patients) Tornado ${ }^{\circledR}$ coils were employed (similar to a. o. $[13,18])$. Coil embolization proved to be highly effective and allowed for complete closure of the target vessels. However, autologous blood clots, detachable balloons, gelatin sponges, and several liquid embolic agents (such as glue and the non-adhesive Onyx ${ }^{\circledR}$ ) have also been shown to perform adequately. The latter impose a higher risk of reopening or are associated with higher costs. In specific anatomical situations as well as in patients with poor coagulation parameters, however, they may be the better choice [13]. Microcoil embolization enables isolation of the vascular lesion while retaining maximal renal vascularization, thus ensuring as much preservation of the renal parenchyma as possible [16].

The intervention was technically successful in $100 \%$ and clinically successful in $89.7 \%$ of our patients. In two patients of our collec- 


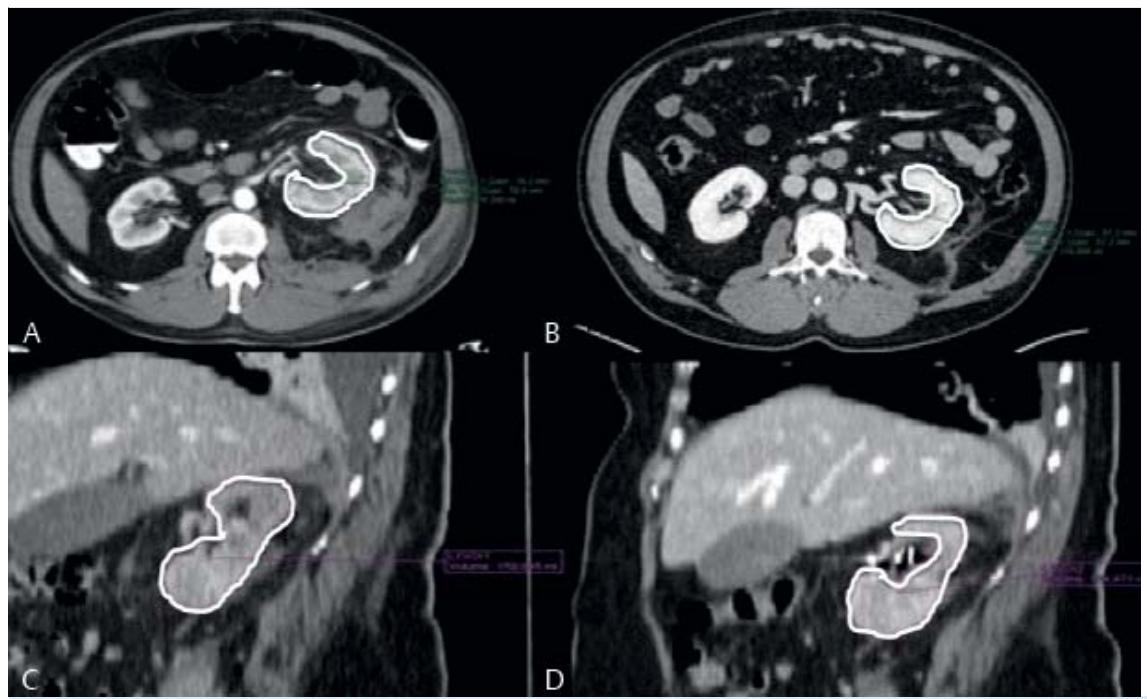

Fig.3 A Volumetric measurement of the left renal parenchyma before embolization. The freehand ROI was carefully drawn around the parenchyma; perirenal hematoma and renal pelvis was not included in the ROI. The pre-interventional volume of the left kidney was $176 \mathrm{ml}$. B Volumetric measurement 2 days after the embolization. Post-interventional renal volume was $139 \mathrm{ml}$, so that the volume loss was $21 \%$. C Volumetric measurement of the left renal parenchyma in another patient. We demonstrate the placement of the ROI in the sagittal MPR. The renal pelvis was spared out of the measurement. The pre-interventional volume was $160 \mathrm{ml}$. D Post-interventional volumetric assessment in the same patient as in C. The postinterventional volume of the left kidney is $135 \mathrm{ml}$, consistent with $15.6 \%$ parenchymal loss.
Abb.3 A Volumetrie des linken Nierenparenchyms vor Embolisation. Die freihand-ROI wurde sorgfältig um das Parenchym gezeichnet; das perirenale Hämatom und das Nierenbecken wurden nicht in die ROI einbezogen. Das präinterventionelle Parenchymvolumen der linken Niere betrug $176 \mathrm{ml}$. B Volumetrische Messung 2 Tage nach Embolisation. Das postinterventionelle Parenchymvolumen betrug $139 \mathrm{ml}$, der Volumenverlust lag daher bei $21 \%$. C Volumetrische Messung des linken Nierenparenchyms in einem weiteren Patienten. Gezeigt wird die Lage der ROI in der sagittalen MPR. Das Nierenbecken wurde von der Messung ausgespart. Das präinterventionelle Volumen lag bei $160 \mathrm{ml}$. D Postinterventionelle volumetrische Messung im selben Patienten wie in C. Das postinterventionelle Volumen lag bei $135 \mathrm{ml}$, vereinbar mit 15,6\% Parenchymverlust. tive, a second transcatheter embolization was required, which resulted in good clinical success, as demonstrated by absence of bleeding in DSA and normalization of blood pressure and renal function. These high success rates are in agreement with those reported in literature $[12,13,16,17,25]$. In four patients, the vascular lesions could not be managed with transarterial embolization, so radical nephrectomy was required for three of them and operative suture of vessels was necessary for the other one. No typical complications of invasive angiography, such as dissections, groin hematoma, or bleeding, were observed; this demonstrates that angiographic microembolization performed by experienced interventional radiologists is a safe procedure.

A review of the eGFR values before and immediately after surgery and transcatheter embolization shows that renal function significantly decreased after partial nephrectomy. Embolization of the vascular lesions, however, did not impair renal function any further as measured by eGFR. These observations are similar to those reported by Gahan et al. [11]. Interestingly, although they found that patients with diabetes mellitus did show a greater decrease in eGFR values before and after intervention, statistical significance was absent, likely because of the small patient sample. To our knowledge, we are the first to quantitatively evaluate renal parenchymal volume before and after coil embolization procedures ( Fig. 3). We observed a mean loss of volume of $25.2 \%$ of renal parenchyma after embolization, which suggests a significant reduction of functional renal parenchyma. However, this volume loss of renal parenchyma was not associated with a significant reduction of renal function, as proven by eGFR measurements. Only one recently published study has semiquantitatively assessed renal parenchymal volume loss after embolization [26].
They reported a mean volume loss of $5 \%$ with a range of $1-50 \%$, which is in line with the range of our study.

Radiation exposure in patients associated with embolization of pseudoaneurysms and arteriovenous fistulas following partial nephrectomy has not been reported previously. The mean dose area product was $8563 \mathrm{cGy} \times \mathrm{cm}^{2}$, with a wide range of $1287-$ $36701 \mathrm{cGy} \times \mathrm{cm}^{2}$. The wide range may be due to the different generations of angiographic equipment used during the tenyear period of the study as well as the different extent and severity of the vascular lesions treated, which is also reflected in the wide range of coils used $(1-26)$. More effort should be made to reduce the radiation doses of these interventions in the future. The mean fluoroscopy time was 13 minutes, which is an acceptably low exposure time. Nevertheless, a shortening of the latter could reduce the radiation effect since a correlation exists between the two [27]. Several limitations of this study inherent to its retrospective nature and small sample size have to be taken into account. However, since pseudoaneurysms and arteriovenous fistulas following partial nephrectomy are rare, our study group is the largest reported to date. The analysis of renal function was performed by determining the eGFR according to the Cockgroft-Gault formula, which is only an approximate indicator of renal function. Volumetric analysis of the renal parenchyma could only be performed in a small subgroup $(n=10)$. This was due to the fact that in the remaining 29 patients, post-interventional renal volume could not be determined because patients were either lost to follow-up or underwent follow-up in a different hospital or private practice or underwent follow-up by MRI. Moreover, the time interval between embolization and the follow-up CT was variable. Finally, a long-term follow-up of the kidney function would provide more information. 


\section{Conclusion}

\section{$\nabla$}

Transcatheter angioembolization is a promising method for treating pseudoaneurysms and arteriovenous fistulas, which are rare but dangerous vascular complications which may occur after partial nephrectomy. Our results show a high technical success rate and no significant decrease in renal function in the early post-embolization period. We assessed the changes in parenchymal volume and radiation doses to which patients are exposed during intervention. In order to provide a clear answer as to which method of diagnosis and angioembolization treatment is superior with regard to maintaining as much renal function as possible, large-scale prospective studies, including a long-term follow-up of renal function, should be performed.

\section{Clinical Relevance of the Study}

- Renal pseudoaneurysms and arteriovenous fistulae can be treated successfully and safely with endovascular embolization.

- Although embolization reduces the renal parenchymal volume, it preserves the organ and its function.

- Arterial lesions, which occur after partial nephrectomy should therefore be treated first with embolization by interventional radiologists.

\section{References}

1 Patard JJ, Shvarts O, Lam JS et al. Safety and efficacy of partial nephrectomy for all $\mathrm{T} 1$ tumors based on an international multicenter experience. The Journal of urology 2004; 171: 2181 -2185, quiz 2435

2 Pahernik S, Roos F, Hampel C et al. Nephron sparing surgery for renal cell carcinoma with normal contralateral kidney: 25 years of experience. The Journal of urology 2006; 175: 2027-2031

3 Budiharto T, Joniau S, Lerut E et al. Prospective evaluation of 11C-choline positron emission tomography/computed tomography and diffusion-weighted magnetic resonance imaging for the nodal staging of prostate cancer with a high risk of lymph node metastases. European urology 2011; 60: 125-130

4 Crepel M, Jeldres C, Perrotte $P$ et al. Nephron-sparing surgery is equally effective to radical nephrectomy for T1BN0M0 renal cell carcinoma: a population-based assessment. Urology 2010; 75: 271-275

5 Thompson RH, Siddiqui S, Lohse CM et al. Partial versus radical nephrectomy for 4 to $7 \mathrm{~cm}$ renal cortical tumors. The Journal of urology 2009; 182: $2601-2606$

6 MacLennan S, Imamura M, Lapitan MC et al. Systematic review of perioperative and quality-of-life outcomes following surgical management of localised renal cancer. European urology 2012; 62: 1097-1117

7 Huang WC, Levey AS, Serio AM et al. Chronic kidney disease after nephrectomy in patients with renal cortical tumours: a retrospective cohort study. The lancet oncology 2006; 7: 735-740

8 Stephenson AJ, Hakimi AA, Snyder ME et al. Complications of radical and partial nephrectomy in a large contemporary cohort. The Journal of urology 2004; 171: $130-134$
9 Jain S, Nyirenda T, Yates J et al. Incidence of renal artery pseudoaneurysm following open and minimally invasive partial nephrectomy: a systematic review and comparative analysis. The Journal of urology 2013; 189: $1643-1648$

10 Hyams ES, Pierorazio P, Proteek $O$ et al. latrogenic vascular lesions after minimally invasive partial nephrectomy: a multi-institutional study of clinical and renal functional outcomes. Urology 2011; 78: 820-826

11 Gahan JC, Gaitonde M, Wadskier L et al. Renal function outcomes following selective angioembolization for iatrogenic vascular lesions after partial nephrectomy. Journal of endourology/Endourological Society 2013; 27: 1516-1519

12 Ghoneim TP, Thornton RH, Solomon SB et al. Selective arterial embolization for pseudoaneurysms and arteriovenous fistula of renal artery branches following partial nephrectomy. The Journal of urology 2011; 185: $2061-2065$

13 Tinto HR, Di Primio M, Tselikas L et al. Selective arterial embolization of life-threatening renal hemorrhage in four patients after partial nephrectomy. Diagnostic and interventional imaging 2014; 95: 601-609

14 Baumann C, Westphalen $K$, Fuchs $H$ et al. Interventional management of renal bleeding after partial nephrectomy. Cardiovascular and interventional radiology 2007; 30: $828-832$

15 Cockcroft DW, Gault MH. Prediction of creatinine clearance from serum creatinine. Nephron 1976; 16: 31-41

16 Shapiro EY, Hakimi AA, Hyams ES et al. Renal artery pseudoaneurysm following laparoscopic partial nephrectomy. Urology 2009; 74: 819823

17 Netsch C, Bruning R, Bach T et al. Management of renal artery pseudoaneurysm after partial nephrectomy. World journal of urology 2010; 28: $519-524$

18 Helck A, Hoffmann RT, Sommer WH et al. Diagnosis, therapy monitoring and follow up of renal artery pseudoaneurysm with contrast-enhanced ultrasound in three cases. Clinical hemorheology and microcirculation 2010; 46: 127-137

19 Jung S, Min GE, Chung BI et al. Risk factors for postoperative hemorrhage after partial nephrectomy. Korean J Urol 2014; 55: 17-22

20 Lane BR, Novick AC, Babineau D et al. Comparison of laparoscopic and open partial nephrectomy for tumor in a solitary kidney. The Journal of urology 2008; 179: 847-851; discussion 852

21 Parsons JK, Schoenberg MP. Renal artery pseudoaneurysm occurring after partial nephrectomy. Urology 2001; 58: 105

22 Cohenpour M, Strauss S, Gottlieb P et al. Pseudoaneurysm of the renal artery following partial nephrectomy: imaging findings and coil embolization. Clinical radiology 2007; 62: 1104-1109

23 Kruger K, Siakavara E. Coil embolization for treatment of vascular complications after nephron-sparing surgery. Acta Radiol 2012; 53: $551-555$

24 Li L, Zhang $Y$, Chen $Y$ et al. A multicentre retrospective study of transcatheter angiographic embolization in the treatment of delayed haemorrhage after percutaneous nephrolithotomy. Eur Radiol 2015; 25: $1140-1147$

25 Ierardi AM, Floridi C, Fontana $F$ et al. Transcatheter embolisation of iatrogenic renal vascular injuries. Radiol Med 2014; 119: 261-268

26 Guneyli S, Gok M, Bozkaya $\mathrm{H}$ et al. Endovascular management of iatrogenic renal arterial lesions and clinical outcomes. Diagn Interv Radiol 2015; $21: 229-234$

27 Pitton MB, Kloeckner R, Schneider J et al. Radiation exposure in vascular angiographic procedures. Journal of vascular and interventional radiology: JVIR 2012; 23: 1487-1495 